\title{
PECULIARITIES OF APPLICATION OF SUPERCAPACITORS IN DEVICES FOR PULSE WELDING TECHNOLOGIES
}

\author{
A.E. KOROTYNSKY, N.P. DRACHENKO and V.A. SHAPKA \\ E.O. Paton Electric Welding Institute, NASU \\ 11 Bozhenko Str., 03680, Kiev, Ukraine. E-mail: office@paton.kiev.ua
}

\begin{abstract}
The prospective areas of application of supercapacitors (SC) are resistance spot welding, resistance butt welding as well as pulse-arc welding, where they can be used as slope controllers. Main technical characteristics of SC and bank of SC (BSC), based on series connection of separate SC, are given. Provided are the main calculation relationships, designed for evaluation of electric parameters of BSC, charge-discharge characteristics for developed BSC are experimentally determined. It is shown that the main disadvantage of series connection of SC cells in the bank is a voltage spread, which is proposed to be eliminated in present work by means of application of special charging device - equalizer. Different schemes of equalizers are considered, their advantages and disadvantages when using in pulse current generators are described. Relevance of application of energy-saving scheme of equalizer for pulse welding methods is shown. Scheme of such a device is proposed and described and calculation relationships providing analytical description of its operation are presented. A scheme for resistance spot welding, based on equalizer and bank of 6 SC is given as an example and technical characteristics of the proposed device are presented. 7 Ref., 1 Table, 6 Figures.
\end{abstract}

Keywords: pulse welding, pulse current generators, slope controllers, supercapacitor, bank of supercapacitors, charge-discharge characteristics, equalizer

Application of electric pulse energy storages is extremely efficient in some welding processes. This, first of all, refers to resistance spot welding [1], resistance butt welding [2], stud welding

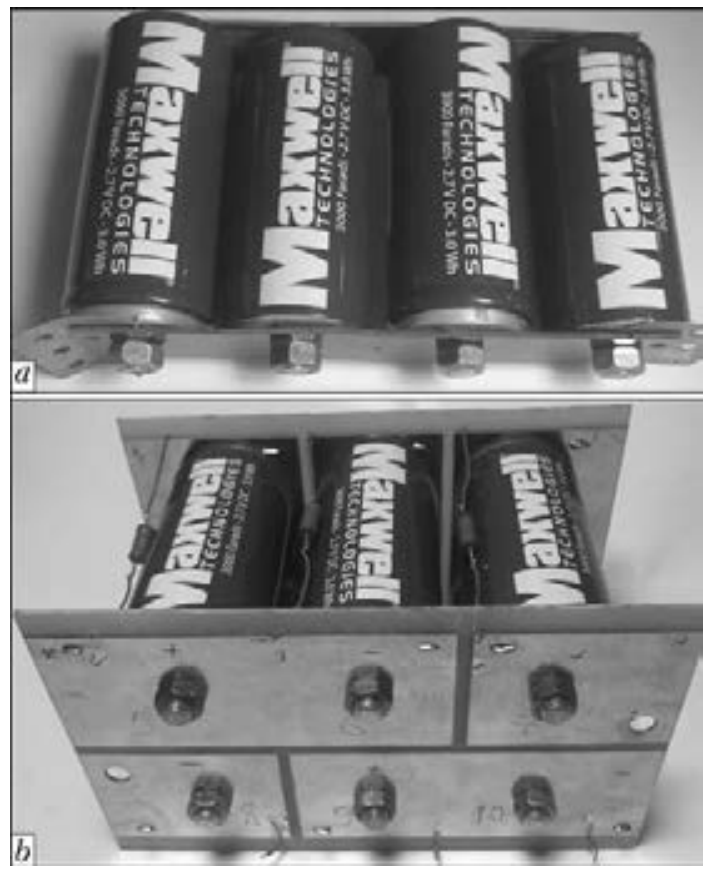

Figure 1. Examples of assembly of series BSC based on 4 (a) and 6 (b) cells

(C) A.E. KOROTYNSKY, N.P. DRACHENKO and V.A. SHAPKA, 2014
[3] as well as gas-shielded pulse-arc welding [4], where they are used as pulse slope controllers. The authors of present work have positive experience of application of capacitor storages in arc cutting, where pulse effect, in contrast to air-arc cutting, is created by current pulse, that allows significant equipment simplification.

Simplicity of switching of bank of capacitors during charge and discharge and possibility of strict dosing of accumulated energy due to regulation of level of charge voltage or duration of pulse effect are to be referred to significant advantages of the capacitor storages, that expands their application in pulse technologies. Capacitor banks, based on cells with double-electric layer - supercapacitors (SC) - find more and more application at present time as capacitor storages. Still, SC cells are connected in the banks for receiving of necessary electric characteristics of the storages due to low level of operating voltage of SC cell $\left(U_{\mathrm{SC}} \leq 2.7 \mathrm{~V}\right)$. However, there are specific difficulties in manufacture of the banks with series SC (BSC) because of technological spread of capacity values of SC in the ranges of one nominal. Figure 1 shows the examples of performance of such BSC for 4 and 6 cells.

Account must be taken of $C_{\Sigma}(n)=C i / n$, $U_{\Sigma}(n)=n U_{i}$ (where $C_{i}$ is the capacity of separate $\mathrm{SC}$; $U_{i}$ is its operating voltage) in calculation of energy, accumulated in series BSC. Hence, it follows according to known formulae that energy 
Characteristics of SC used for series BSC

\begin{tabular}{||c|c|c|c|c|c|c|}
\hline BSC type & $\begin{array}{c}\text { Quantity } \\
\text { of cells }\end{array}$ & $C, \mathrm{~F}$ & $\begin{array}{c}R, \\
\mu \mathrm{Ohm}\end{array}$ & $\begin{array}{c}\tau=R C, \\
\mathrm{~s}\end{array}$ & $U_{\mathrm{op}}, \mathrm{V}$ & $W, \mathrm{~J}$ \\
\hline BSC-4 & 4 & 750 & 0.96 & 0.72 & 10.8 & 43,740 \\
\hline BSC-6 & 6 & 500 & 1.44 & 0.72 & 16.2 & 65,610 \\
\hline BSC-10* & 10 & 300 & 2.44 & 0.72 & 27 & 109,350 \\
\hline
\end{tabular}

${ }^{*}$ BSC-10 is the structure with series BSC-4 and BSC-6.

$$
W(n)=\frac{C_{\Sigma}(n)\left(U_{\Sigma}(n)\right)^{2}}{2}=\frac{n C_{i} U_{i}^{2}}{2}=n W_{i} .
$$

Technical characteristics of applied SC are given in the Table.

Voltage is usually non-uniformly distributed in the cell during operation of such banks and it will be in inverse proportion to the values of capacity in circuit of series capacitors: $U_{1} C_{1}=$ $=U_{2} C_{2}=U_{3} C_{3}=U_{n} C_{n}$. Therefore, factor of nonuniform distribution of voltages in the circuit of series SC should be taken into account in charging of such a bank and stop charging process after achievement of maximum voltage $U C_{i}=U_{C \max }$ by any of capacitors. At that total voltage at capacitor bank will be lower than nominal one: $U_{\mathrm{b}} \leq$ $\leq n U_{C \max }=U_{\mathrm{b} \max }$ or $\Delta U_{\mathrm{b} \max }=U_{\mathrm{b} \max }-U_{\mathrm{b}}$.

Experimental investigations of voltage spread in BSC cells in the process of test operation were carried out at test bench, scheme of which is shown in Figure 2. Obtained test results were used for plotting of histograms of distribution of voltage in BSC cells (Figure 3), consisting of 10 series SC of VSAR3000 R270 K05 type. Results of investigation of SC behavior in mode of longterm storage of electric charge are given in $\mathrm{Fi}^{-}$ gure 4. Obtained experimental data showed that series connection of power SC provides for problems, related with undercharging of separate elements of BSC, that reduces to significant extent energy efficiency of pulse generator.

This work is dedicated to elimination of given effect and, thus, increase of energy efficiency of pulse generators, made using SC.

Preliminary selection of SC on values of capacity and assembly of banks from SC cells with similar capacity are carried out in order to provide equal voltage at cells and $U_{\mathrm{b}}=U_{\mathrm{b} \max }$ in charge of bank of series SC. However, some charge of capacity of SC cells is possible in process of SC operation, that can result in not always uniform distribution of voltages in BSC cells (see $\mathrm{Fi}^{-}$ gure 3). At present time, the equalizer type devices are used for voltage adjustment at BSC cells for the purpose of more efficient application of energy properties of SC in the course of the

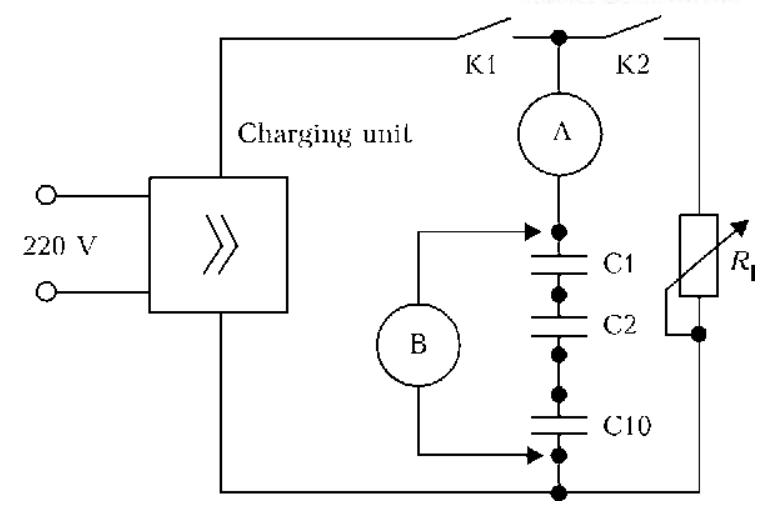

Figure 2. Scheme of experimental bench for verification of BSC: K1, K2 - switching units; C1-C10 - capacitor cells

whole guaranteed period of operation. There are different types of equalizers, i.e. passive dissipative [5], active dissipative [6] and active energysaving [7].

Designing of systems for SC recharging using the active energy-saving equalizers is proposed
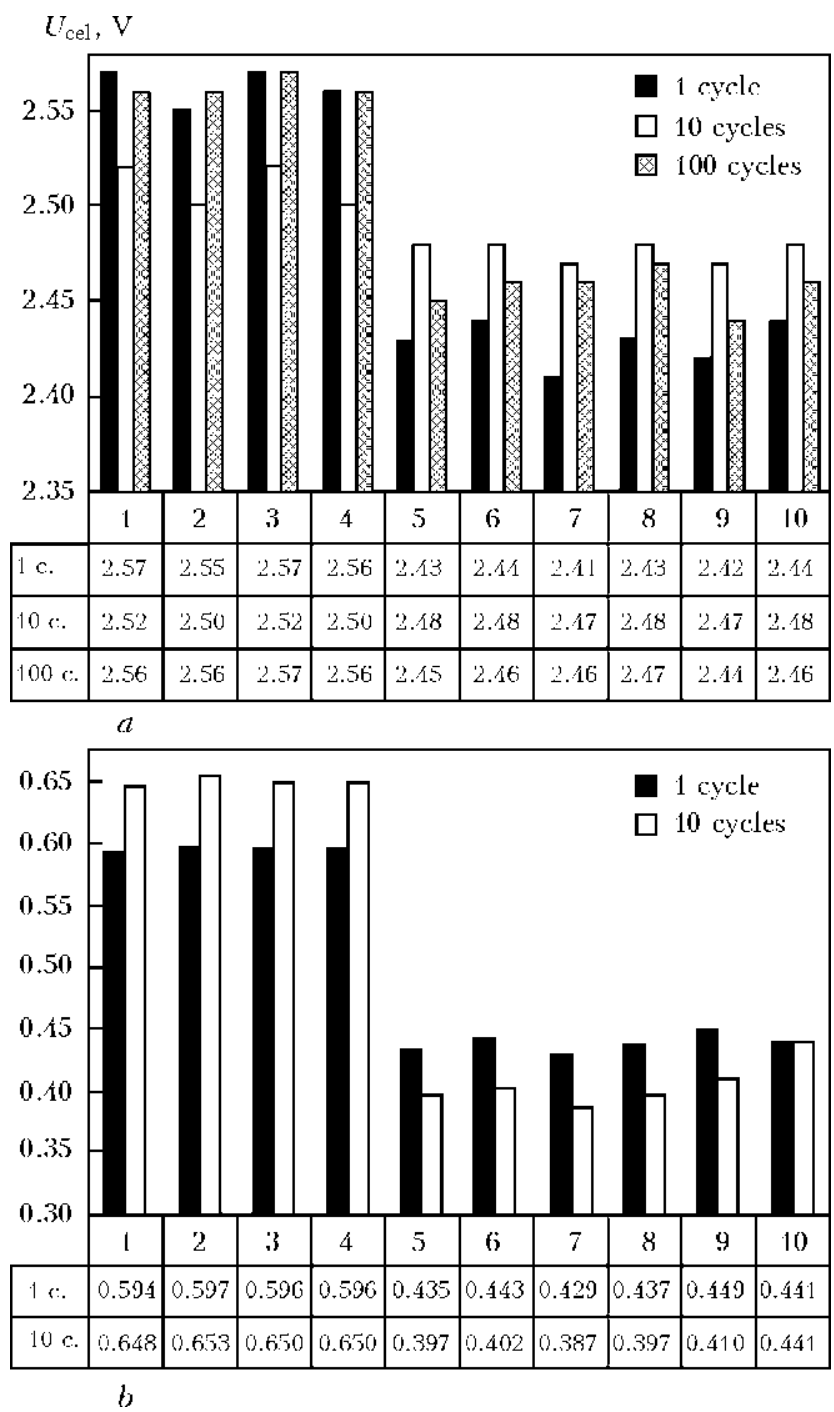

Figure 3. Histograms of distribution of voltages in cells 1-10 of charged ( $a$ ) and uncharged (b) BSC at different quantity of charge-discharge operating cycles 


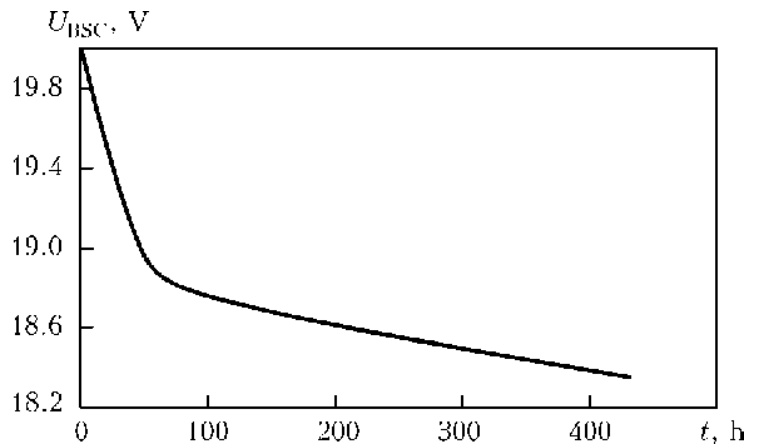

Figure 4. Self-charging of bank from 10 series SC

for consideration due to modern requirements to ecology of energy systems and energy-saving.

Principle of their work is based on application of BSC cell energy-exchanging processes, at that the cells with increased voltage are used for recharging of the cells with reduced one. Uniform distribution of voltages in the circuit, virtually for the whole voltage operating range of the bank, is maintained in BSC as a result of work of such a system in the process of energy exchange between the cells. Earlier similar hardware means $[6,7]$ were used in operation of power lithium-ion banks in different mobile and aerospace devices. The lithium-ion banks are very similar to BSC

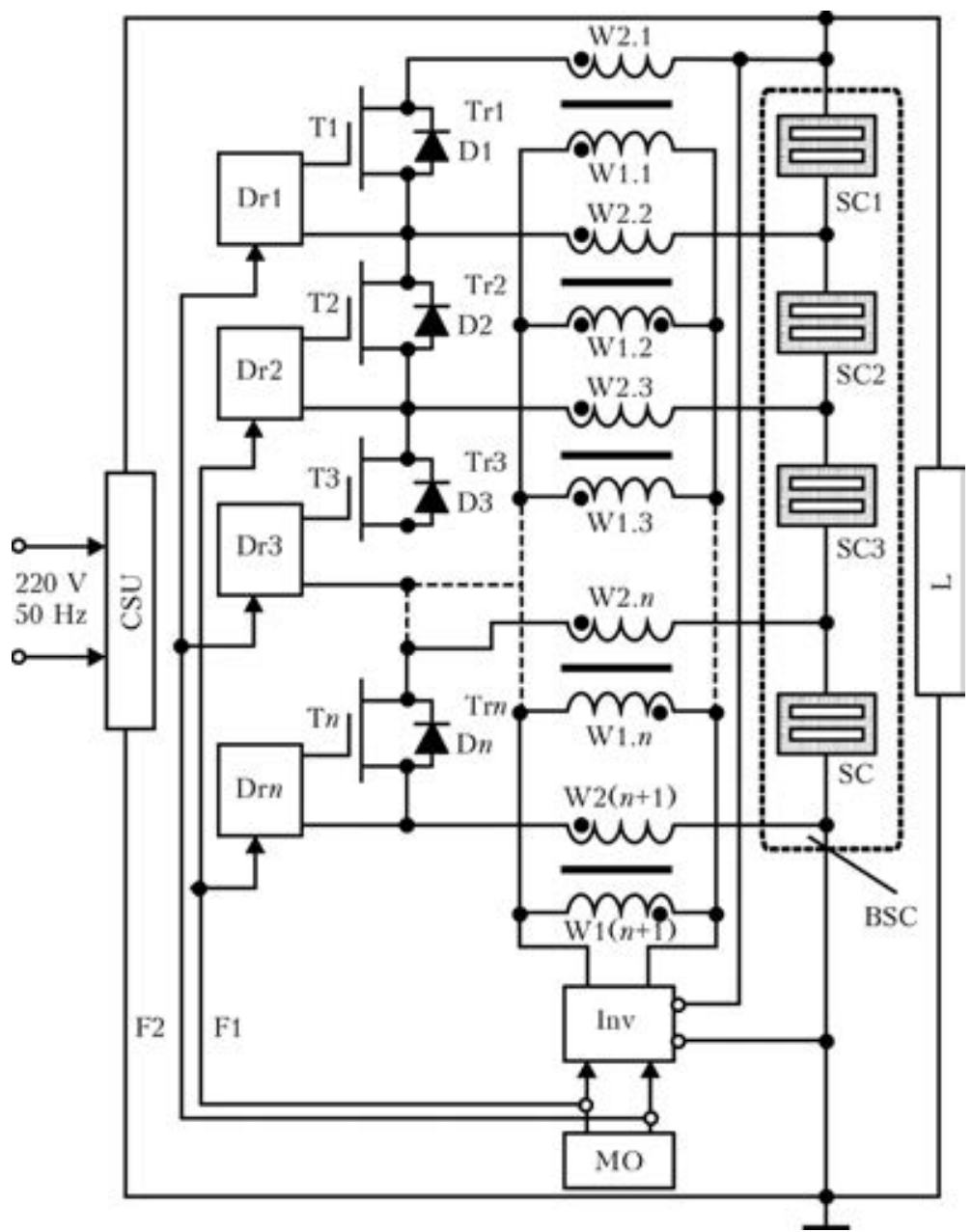

Figure 5. Scheme of BSC equalizer (see designations in the text) in some characteristics (for example, they are characterized by directly proportional dependence of voltage in cell on charge level), therefore the similar approaches to equalizers can be used for BSC. The example of such adapted equalizer scheme applicable to SC is shown in Figure 5.

The scheme includes a charging supply unit (CSU), designed for formation of BSC charge current from primary mains, series supercapacitors SC1-SCn, where their quantity is determined by the requirements to load supply. Scheme of active equalizer is based on matching transformers $\operatorname{Tr} 1-\operatorname{Tr}(n+1)$ and electronic power switches T1-T $n$. Diodes D1-D $n$ are integrated in a structure of crystal of electronic power switch. Drivers Dr1-Drn are designed for matching of switch drive circuits $\mathrm{T} 1-\mathrm{T} n$ with regulation scheme. Regulation scheme of master oscillator (MO) is performed on standard two-phase PWM controller, at that output of the first phase $\mathrm{F} 1$ is connected to uneven, and the second F2 to even switchers of the scheme. High-frequency inverter (Inv) is designed for parallel supply of matching transformers for adjustment of voltage between even and uneven groups of cells. In process of device operation the capacitor bank is charged from CSU or discharged into load ( $\mathrm{L}$ ). If voltages at all capacitors are equal, voltage $U_{\mathrm{W} 2 i}=$ $=U_{\mathrm{SC} i} / 2-\Delta U_{\mathrm{VT} i}$ (where $\Delta U_{\mathrm{VT} i}$ is the overbalance voltage) is supplied to secondary windings $\mathrm{W} 2.1-\mathrm{W} 2(n+$ +1 ) of matching transformers $\operatorname{Tr} 1-$ $\operatorname{Tr}(n+1)$. Voltage at secondary windings of the transformers is determined from $U_{\mathrm{W} 2 i} \approx U_{\mathrm{BSC}} / 2 n$ condition, when voltage at the primary windings $U_{\mathrm{W} 1 i}=U_{\mathrm{BSC}}$.

If voltage at any of the capacitors is more or less than average one $\left(U_{\mathrm{SC}}\right.$ av $\left.\neq U_{\mathrm{BSC}} / n\right)$, then equalizing currents start to flow through windings of Tr1$\operatorname{Tr}(n+1)$ and open switches $\mathrm{T} 1-\mathrm{T} n$, resulting in voltage balancing at the capacitors. Matching inverter operates synchronously with switching of T1Tn switches and in turn carries out recharging of even and uneven groups of capacitors, thus balancing voltages between the groups. Operation of the scheme results in balancing of voltages at $\mathrm{SC}$ cells and reduction of values of equalizing currents to the minimum. Currents in primary windings of the transformers are reduced to the values determined by losses of transformer 


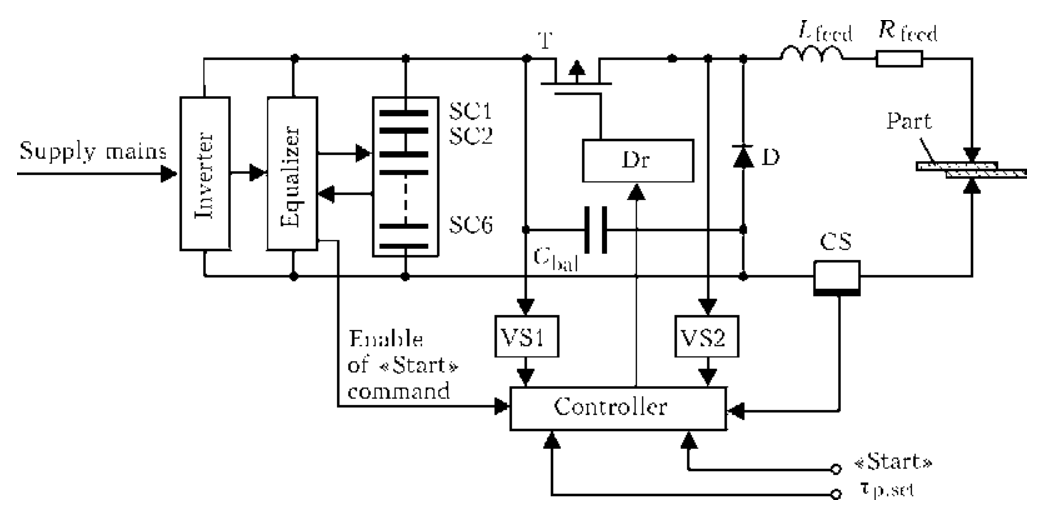

Figure 6. Example of application of equalizer in resistance spot welding device

open-circuit. Balancing of voltages at BSC cells is carried out exactly in such a way.

The peculiarity of this device (see Figure 5), making it different from described in work [7], is application of separate sections of matching transformers for each SC cell as well as replacement of the diodes for synchronous rectifiers (field-controlled transistor), that provided higher rate and accuracy of voltage balancing.

Compare energy parameters of BSC in use of scheme of active equalizer (see Figure 5).

Energy, accumulated in BSC with series capacitor cells, is determined by the expression

$$
E_{\mathrm{BSC}}=\frac{n C_{0} U_{0}^{2}}{2},
$$

where $n$ is the quantity of cells; $C_{0}$ is the nominal capacity; $U_{0}$ is the nominal voltage.

If BSC has a capacitor cell with reduced capacity

$$
C_{i}=k C_{0},
$$

(where $k<1$ is the coefficient of undercharging of separate cell), charged to nominal voltage $U_{C i}=U_{0}$, then voltage at remaining cells with nominal voltage will equal

$$
U_{x}=k U_{0}\left(k C_{0} U_{0}=C_{0} U_{x}\right) .
$$

It follows from this that sum voltage at such a bank with series cells

$$
U_{\mathrm{BSC}}=U_{0} k(n-1)+U_{0}=U_{0}(1+k(n-1)) .
$$

Energy, accumulated by BSC, including one capacitor cell with reduced capacity, will equal

$$
\begin{gathered}
E_{\mathrm{BSC}}^{\prime}=\frac{C_{\mathrm{BSC}}^{\prime} U_{\mathrm{op}}^{\prime}}{2}= \\
=\frac{C_{0} \frac{k}{1+k(n-1)}\left[U_{0} k(n-1)+U_{0}\right]^{2}}{2}= \\
=\frac{C_{0} U_{0}^{2} k(1+k(n-1))}{2} .
\end{gathered}
$$

Energy accumulated in BSC in use of equalizer, balancing the voltage at capacitor cells, is

$$
\begin{gathered}
E_{\mathrm{BSC}}^{\prime \prime}=\frac{C_{\mathrm{BSC}}^{\prime \prime} U_{\mathrm{op}}^{\prime \prime 2}}{2}=\frac{C_{0} \frac{k}{1+k(n-1)}\left(n U_{0}\right)^{2}}{2}= \\
=\frac{C_{0} U_{0}^{2}}{2} \frac{k n^{2}}{1+k(n-1)} .
\end{gathered}
$$

Comparative analysis of energy efficiency of equalizer application can be carried out with the help of given expressions (4)-(6). If coefficient of efficiency of BSC with similar cells is taken for $K_{\text {ef }}=1$, then efficiency of BSC with cell, having reduced capacity, will be determined by relationship

$$
\begin{gathered}
K_{\mathrm{ef} 1}=\frac{E_{\mathrm{BSC}}^{\prime}}{E_{\mathrm{BSC}}}=\frac{k C_{0} U_{0}^{2}[1+k(n-1)]}{n C_{0} U_{0}^{2}}= \\
=\frac{k^{2}(n-1)+k}{n},
\end{gathered}
$$

and efficiency of BSC with equalizer and cell, having reduced capacity, is

$$
K_{\mathrm{e} 22}=\frac{E_{\mathrm{BSC}}^{\prime \prime}}{E_{\mathrm{BSC}}}=\frac{\frac{k n^{2}}{1+k(n-1)}}{n}=\frac{k n}{1+k(n-1)} .
$$

Therefore, fractional increase of BSC efficiency with equalizer will be determined by relationship

$$
Q=1-\frac{K_{\mathrm{ef} 1}}{K_{\mathrm{ef} 2}}=1-\left(\frac{k(n-1)+1}{n}\right)^{2} .
$$

Use of given calculation relationship (7)-(9) for estimation of energy efficiency of the equalizer allows proving that significant effect is noted even at $10 \%$ deviation of capacity of only one capacitor from nominal value.

It is necessary to outline that application of equalizers in different devices for pulse welding technologies allows reaching not only high energy indices, but providing high stability of weld- 
ing-technological indices due to precision BSC charging.

Figure 6 as an example shows a scheme of device for resistance spot welding. Its main difference from known devices [1] is presence of the equalizer. Inverter of charging current after switching of electric supply provides charging of capacitors SC1 and SC6 to a level of voltage, determined by controller, after what the scheme is transformed in a waiting mode. Simultaneously, the equalizer scheme analyzes balancing of voltages in SC cells and, if necessary, carries out active balancing of voltages in BSC cells. «Start» command blocks the operation of charging inverter and regulation pulse is supplied to driver of current switch $\mathrm{T}$. As a result, emergence of pulse of operating current, flowing along circuit: SC1-SC6, T, $L_{\text {feed }}, R_{\text {feed }}, \mathrm{CS}, \mathrm{SC} 1-\mathrm{SC} 6$, is observed. Welding device allows dosing of energy, supplied to contact gap by means of programming of SC1-SC6 voltage and duration of current pulse, determined by switching unit. Duration of current pulse can be varied in the ranges from units to several hundred milliseconds. Also, series of pulses with individual parameters for each pulse in the series is possible. Information, received from current and voltage sensors CS and VS2, is used for control and regulation of energy, supplied to the contact gap of part being welded. High technological indices in given device are achieved due to application of high-speed electron current switching unit, which carries out accurate dosing of energy, supplied to welding zone.

Experimental check of the device for resistance spot welding, assembled on given scheme (see Figure 6), provides for the following results: maximum welding current equals $1200 \mathrm{~A}$; consumed energy makes $2 \mathrm{VA}$ in open-circuit mode, $500 \mathrm{VA}$ in BSC charge mode and $100 \mathrm{VA}$ in welding mode at supply from single-phase mains $220 \mathrm{~V}$. Smoothly regulated duration of welding current pulse is at the level of $0.01 \div 0.5 \mathrm{~s}$.

In practice the $\mathrm{SC}$ cells should be connected in the banks for receiving of necessary and ac- ceptable load resistance of the capacitor storage. Quantity of series cells in such a bank determines its operating voltage, and number of parallel branches is defined by its maximum operating current and efficiency, that should be considered in BSC designing. Due to the fact that SC has some internal loss resistance $R_{0}$, energy accumulated in it during discharge is released for load resistance $R_{1}$ as well as $R_{0}$. Obviously that the higher $R_{0}$ in relation to $R_{1}$, the lower is the level of loss in SC and, as a result, the lower is the level of energy-conversion efficiency in load during its operation. Clearly that it is necessary to be assumed in BSC use. Moreover, it is desirable to consider not only the effect of bank and its weight-dimension indices, but environment requirements of electrical consumers as well as economy criterion, determined among other by cost of electric energy and operation expenses, for designing of current welding equipment and other technological equipment using BSC as energy storage.

1. Paton, B.E., Korotynsky, A.E., Drachenko, N.P. et al. (2009) Application of supercapacitors for increase the power efficiency of devices for spot resistance welding. In: Proc. of Int. Sci.-Pract. Conf. on Power- and Resources-Saving in Industry, Power Engineering and Transport (Kiev, 2009), 54-58.

2. Kuchuk-Yatsenko, S.I., Lebedev, V.K. (1976) Continuous flash-butt welding. Kiev: Naukova Dumka.

3. Paton, B.E., Drachenko, M.P., Kaleko, D.M. et al. Apparatus for stud welding. Pat. 92389 Ukraine. Int. Cl. B 23 K 9/20. Publ. 25.10.2010.

4. Korotynsky, A.E. (2002) State-of-the-art, tendencies and prospects of development of high-frequency welding converters (Review). The Paton Welding J., 7, 44-47.

5. Shurygina, V. (2003) Supercapacitors as the helpers or competitors to battery power sources. Electronics: science, technology, business, Vol. 3, 20-24.

6. Cizov, M. (2003) Device for voltage rectification on elements of supercapacitor bank. Sovr. Elektronika, 1, 40-43.

7. Eremenko, V., Vorontsov, K., Varlamov, D. (2007) Hardware methods of increase in power efficiency of high-voltage accumularor bank. Elektr. Komponenty - Ukraina, 7/8, 62-66.

Received 21.10.2013 